\title{
Illumination of Conjugated Polymer in Solution Alters its Conformation and
}

\section{Thermodynamics}

\section{Supporting Information}

This supporting information contains graphical representation of the Zimm Plot analysis of SANS data described in the text.

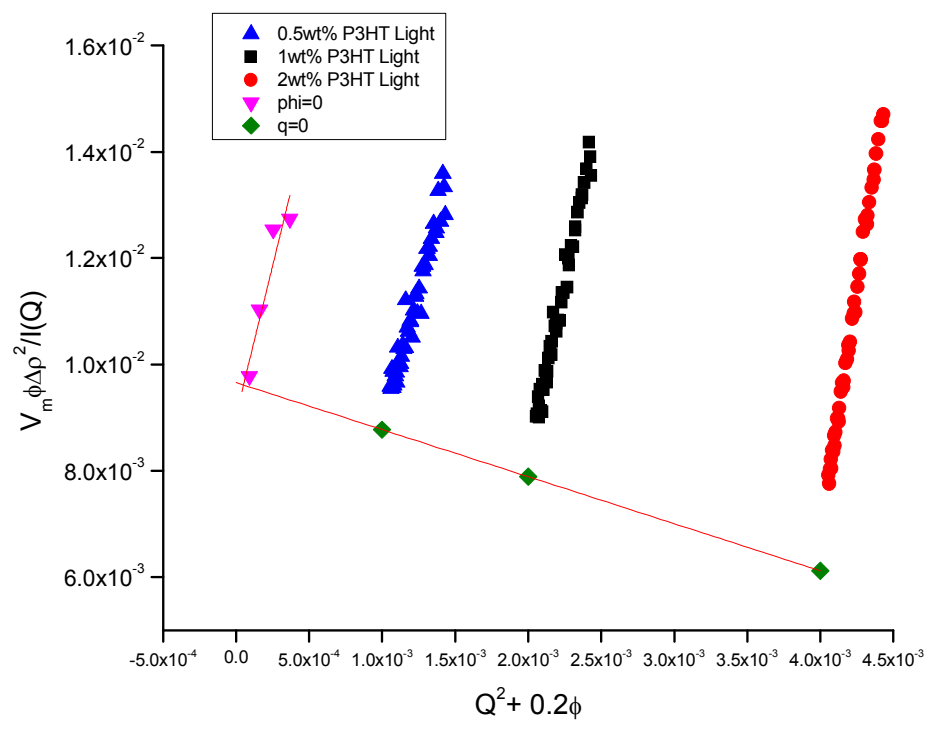

Figure S1: Zimm plot of P3HT in d-Styrene under white light illumination. $0.5 \mathrm{wt} \%$ sample denoted by blue traces, $1 \mathrm{wt} \%$ by black, and $2 \mathrm{wt} \%$ by red. 